\title{
White spot syndrome virus VP37 interacts with VP28 and VP26
}

\author{
Qing-Hui Liu ${ }^{1, *}$, Cui-Yan Ma ${ }^{1,2}$, Wen-Bo Chen ${ }^{1,3}$, Xiu-Li Zhang ${ }^{1,4}$, Yan Liang ${ }^{1}$, \\ Shuang-Lin Dong ${ }^{2}$, Jie Huang ${ }^{1, * *}$
}

\author{
${ }^{1}$ Yellow Sea Fisheries Research Institute, Chinese Academy of Fishery Sciences, No.106 Nanjing Road, Qingdao 266071, PR China \\ ${ }^{2}$ Oceanic University of China, No. 5 Yu Shan Road, Qingdao, PR China \\ ${ }^{3}$ Liao Ning Normal University, DaLian, PR China \\ ${ }^{4}$ Scientific and Technology University of Qingdao, Qingdao, PR China
}

\begin{abstract}
White spot syndrome virus (WSSV) is one of the most virulent pathogens affecting penaeid shrimp, causing high mortality in infected populations. Interactions between virus structural proteins are likely to be important for virus assembly. Many steps of the WSSV assembly and maturation pathway remain unclear. In the present study, the interaction between VP37 and envelope or nucleocapsid proteins was characterized. VP37 was expressed in Escherichia coli and confirmed by Western blotting. Pure WSSV virions were subjected to Triton X-100 treatment to separate the envelope and nucleocapsid fractions. Overlay assays showed that VP37 interacted with VP28 and VP26. The interaction of VP37 with VP28 and VP26 was confirmed further by His pull-down and matrixassisted laser desorption ionization (MALDI) mass spectrographic assays. The binding assay of VP37 with VP28 by ELISA confirmed that the 2 proteins had direct interaction in vivo. This discovery will help elucidate the molecular mechanisms of virion morphogenesis.
\end{abstract}

KEY WORDS: White spot syndrome virus · VP37 · Virus protein interaction

Resale or republication not permitted without written consent of the publisher

\section{INTRODUCTION}

White spot syndrome virus (WSSV) is a major pathogen in shrimp aquaculture but also infects many other crustacean species (Chou et al. 1995, Lo et al. 1996, Chang et al. 1998, Wang et al. 1998, Chen et al. 2000). The virus contains a double-stranded, circular DNA of about $300 \mathrm{~kb}$ that has been sequenced completely in 3 WSSV isolates (van Hulten et al. 2001a, Yang et al. 2001, Chen et al. 2002). On the basis of phylogenetic analysis, WSSV has been classified as the sole member of a novel virus genus, Whispovirus, and family, Nimaviridae (Mayo 2002, Vlak et al. 2005). More than 50 structural proteins have been identified (Huang et al. 2002, Tsai et al. 2004, Li et al. 2007).

Viral structural proteins have critical functions not only in viral structure and assembly but also in the early stages of infection, cell adhesion, signal transduction, and evasion of the rapidly deployed antiviral defenses of the host. Interactions between virus structural proteins are likely to be important for virus assembly. In many enveloped viruses, protein-protein interactions are thought to be essential for virion morphogenesis (Szajner et al. 2003). Many steps along the WSSV assembly and maturation pathway remain unclear. In particular, the acquisition of the virus tegument is a poorly understood process, and the molecular interactions involved in tegument assembly have not yet been defined.

In previous studies, intensive efforts have been made to characterize the individual envelope proteins of WSSV, but little is known about the molecular events occurring during the assembly. Recently, in vitro experiments provided evidence of direct interaction of VP28 with VP26 and VP24 (Xie \& Yang 2006). VP37 is a binding envelope protein involved in infection (Liang et al. 2005, Wu et al. 2005, Liu et al. 2006); it is the product of the WSV254 gene of WSSV (Yang et al. 2001). In the present study, we have separated the 
envelope and nucleocapsid proteins of purified WSSV virions. Interactions were identified between VP37 and other structural proteins. Further exploration of the biochemical interactions of WSSV structural proteins might help to elucidate the molecular mechanisms of virion morphogenesis.

\section{MATERIALS AND METHODS}

Expression and purification of recombinant VP37 and VP28 in Escherichia coli. The WSSV VP37 gene was PCR amplified from WSSV genomic DNA. The WSSV VP28 gene was PCR amplified from WSSV genomic DNA using the forward primer 5'-CTA CTC GAG ATG GAT CTT TCT TTC ACT C-3' and the reverse primer 5'-zTAT AAG CTT TCG GTC TCA GTG CCA-3'. The amplified genes were ligated into $\mathrm{pBAD} / \mathrm{gIII} \mathrm{A}$. The recombinant plasmids were transformed into $E$. coli strain TOP10, and the inserts were confirmed by sequencing.

Cultures of TOP10 carrying the recombinant plasmid were grown in Luria-Bertani medium $(100 \mathrm{ml}$, $50 \mu \mathrm{g} \mathrm{ml}^{-1}$ ampicillin) at $37^{\circ} \mathrm{C}$ with shaking at $300 \mathrm{rpm}$ for 4 to $5 \mathrm{~h}$, until the optical density at $600 \mathrm{~nm}\left(\mathrm{OD}_{600}\right)$ of the cultures reached 0.5 to 0.7 . L-arabinose was then added to a final concentration of $0.2 \%$, and the cultures were incubated for another $5 \mathrm{~h}$ under the same conditions. The Escherichia coli cells were centrifuged at $5000 \times g$ for $10 \mathrm{~min}$, resuspended in Buffer $(6 \mathrm{M}$ guanidine hydrochloride, $0.1 \mathrm{M}$ sodium phosphate, $0.01 \mathrm{M}$ Tris- $\mathrm{HCl}, \mathrm{pH} 8.0$ ) at $5 \mathrm{ml} \mathrm{g}^{-1}$ wet weight, and then centrifuged at $10000 \times g$ for $10 \mathrm{~min}$ at $4^{\circ} \mathrm{C}$. The supernatant was added to Ni-NTA resin. Fractions were collected and analyzed by sodium dodecyl sulphate polyacrylamide gel electrophoresis (SDSPAGE). To obtain native rVP37, the purified rVP37 was recombined against buffer containing $10 \mathrm{mM}$ Tris- $\mathrm{HCl}$, $\mathrm{pH}$ 8.8, $150 \mathrm{mM} \mathrm{NaCl}$, first with $4 \mathrm{M}$ guanidine hydrochloride, then with $2 \mathrm{M}$ guanidine hydrochloride and finally with no guanidine hydrochloride. Each dialysis step was performed for at least $12 \mathrm{~h}$ at $4{ }^{\circ} \mathrm{C}$.

WSSV envelop and nucleocapsid protein prepared. The infection of healthy crayfish Procambarus clarkii and the purification of virus were performed as described previously (Xie et al. 2005). Briefly, the tissues of infected crayfish, excluding the hepatopancreas, were homogenized in TNE buffer $(50 \mathrm{mM}$ Tris$\mathrm{HCl}, 400 \mathrm{mM} \mathrm{NaCl}, 5 \mathrm{mM}$ EDTA, $\mathrm{pH}$ 8.5) and then centrifuged at $3500 \mathrm{~g}$ for $5 \mathrm{~min}$ at $4^{\circ} \mathrm{C}$. After being filtered by nylon net (400 mesh), the supernatant was centrifuged at $30000 \times g$ for $30 \mathrm{~min}$ at $4^{\circ} \mathrm{C}$. Then, the upper loose pellet was rinsed out carefully and the lower white pellet was suspended in $10 \mathrm{ml}$ TN buffer (20 mM Tris- $\mathrm{HCl}, 400 \mathrm{mM} \mathrm{NaCl}, \mathrm{pH}$ 7.4). After cen- trifugation at $3500 \times g$ for $5 \mathrm{~min}$, the virus particles were sedimented by centrifugation at $30000 \times g$ for 20 min at $4^{\circ} \mathrm{C}$, then resuspended and kept in $1 \mathrm{ml} \mathrm{TN}$ buffer. Envelope and nucleocapsid fractions were obtained by treatment with Triton X-100. For the Triton X-100 extraction, intact virions were mixed with an equal volume of $1 \%$ Triton $\mathrm{X}-100$ as well as $0.15 \mathrm{M}$ $\mathrm{NaCl}$, and incubated at $4^{\circ} \mathrm{C}$ for $30 \mathrm{~min}$. The mixture was sedimented at $20000 \times g$ for 20 min to separate the phases. Both phases were subjected to a second round of Triton X-100 extraction. Supernatant and pellet were concentrated by acetone precipitation at $-20^{\circ} \mathrm{C}$ and analyzed by SDS-PAGE. For interaction experiment, the pellet was rinsed with water to eliminate any residual supernatant solution and then resuspended in TN buffer.

Digoxigenin (DIG)-labeled rVP37 protein and interaction analysis. Purified rVP37 protein was dialysed against phosphate-buffered saline (PBS) and labeled with DIG. Redundant DIG was removed by a Sephdeax-50 column. The viral envelope proteins and nuclecapsid proteins were separated by SDS-PAGE, transferred to a polyvinylidene difluoride (PVDF) membrane and renatured gradually at $4^{\circ} \mathrm{C}$ overnight in HEPES buffer (20 mM HEPES, $100 \mathrm{mM} \mathrm{NaCl}, 1 \mathrm{mM}$ EDTA, 1 mM dithiothreitol, $0.1 \%$ Tween 20, $10 \%$ glycerol, $\mathrm{pH}$ 7.5) containing $5 \%$ non-fat milk. After rinsing with Tris-buffered saline (TBS) containing 0.5\% Tween 20, the membrane was incubated with DIGlabeling purified rVP37 for $1 \mathrm{~h}$ at room temperature on a rocking platform. The membrane was washed 3 times with TBS containing $0.5 \%$ Tween 20 . Then antiDIG antibody conjugated with horseradish peroxidase (HRP) was added. After rinsing with TBS, interacting proteins were detected by exposing the membrane to an HRP-substrate kit. DIG-BSA was used as a control.

VP37 interaction with envelope or neclocapsid proteins. A modified His pull-down assay was conducted. The purified His-tagged VP37 was bound to $20 \mu \mathrm{l} \mathrm{Ni}$ nitriloacetic acid (Ni-NTA) beads (Sigma) in $1 \times$ PBS for $2 \mathrm{~h}$ with rotation. Beads were washed twice for $10 \mathrm{~min}$ each in $1 \times$ PBS containing $0.1 \%$ Triton X-100, and once in a binding buffer $(20 \mathrm{mM}$ HEPES, $100 \mathrm{mM}$ $\mathrm{NaCl}, 0.5$ mM EDTA, $0.1 \%$ Triton X-100, $10 \%$ glycerol, protease inhibitor cocktail). The washed beads were incubated in $300 \mu \mathrm{l}$ binding buffer with either of envelope or neclocapsids. Complexes were centrifuged and washed 3 times with the binding buffer to remove nonspecific binding. Bound proteins were eluted in $30 \mu \mathrm{l}$ of Laemmli sample buffer, boiled for $10 \mathrm{~min}$, and analyzed by SDS-PAGE and mass spectrometry analysis. Beads without His-tagged VP37 served as a control.

Mass spectrometry analysis. Coomassie Brilliant Blue-stained protein spots were excised from gels. The gel pieces were minced and allowed to dry before 
trypsin digestion. Matrix-assisted laser desorption ionization-time-of-flight mass spectrometry analysis (MALDI-TOF-MS) was performed, and the MASCOT program was used to analyze the results. The samples were mixed with the matrix $(1: 1, \mathrm{v} / \mathrm{v})$ before loading on the target plate. MALDI-TOF spectra of the peptides were obtained with a Voyager-DE PRO Biospectrometry workstation mass spectrometer (PerSeptive Biosystems). The in-gel digested samples were desalted using ZipTip C18TM (Millipore) and dried. The MALDI-MS was an ABI-4700-TOF-TOF Proteomics Analyzer (Applied Biosystems). The mass range was scanned from 700 to 3200 Da. Myoglobin digested by trypsin was used to calibrate the instrument by internal calibration mode. All the spectra of the test samples were acquired using the default mode. The data were searched by GPS Explorer using MASCOT as the search engine.

Western blot analysis of recombinant VP37 and VP28. The rVP37 or rVP28 protein was separated by SDS-PAGE and transferred to the PVDF membrane. The membrane was blocked in blocking buffer (MPBS: $2 \% \mathrm{BSA}+\mathrm{PBS}$ ) at $4^{\circ} \mathrm{C}$ overnight. After washing, the membrane was incubated with anti-His antibody (1:3000) conjugated with HRP for $1 \mathrm{~h}$ at room temperature. The membrane was then washed and the color was developed with an HRP-substrate kit.

Determination of binding specificity by ELISA. Flatbottomed 96-well ELISA plates (Nunc) were coated with $15 \mu \mathrm{g}$ of either WSSV, purified rVP28, or BSA $(15 \mu \mathrm{g})$. The plates were incubated at $4^{\circ} \mathrm{C}$ overnight and blocked with $150 \mu \mathrm{l}$ of $10 \%$ heat-inactivated fetal bovine serum (FBS, HyClone) diluted in PBS buffer for $2 \mathrm{~h}$ at room temperature. The plates were washed with PBS buffer containing $0.05 \%$ Tween 20, and various dilutions of DIG-labeled rVP37 (0 to $30 \mu \mathrm{g}$ ) were added. After incubation at room temperature for $1 \mathrm{~h}$, the wells were washed 5 times with PBST and 5 times with PBS. Anti-DIG-Fab-HRP diluted with MPBS (PBS $+2 \%$ milk) (1:3000) was added at room temperature for $1 \mathrm{~h}$. The wells were washed 5 times with PBST and PBS. An $o$-phenylenediamine (OPD) substrate (75 $\mu \mathrm{l})$ was added to each well and incubated at $37^{\circ} \mathrm{C}$ until color appeared. The reaction was stopped by adding $50 \mu \mathrm{l}$ of $1 \mathrm{M} \mathrm{H}_{2} \mathrm{SO}_{4}$ to each well. The absorbance at $492 \mathrm{~nm}$ was read using BSA as reference.

\section{RESULTS}

\section{rVP37 protein expression and Western blot analysis}

The VP37 gene was cloned into the pBAD/gIII A vector and expressed in TOP10 cells under induction of $0.2 \%$ L-arabinose. After induction, induced and non-

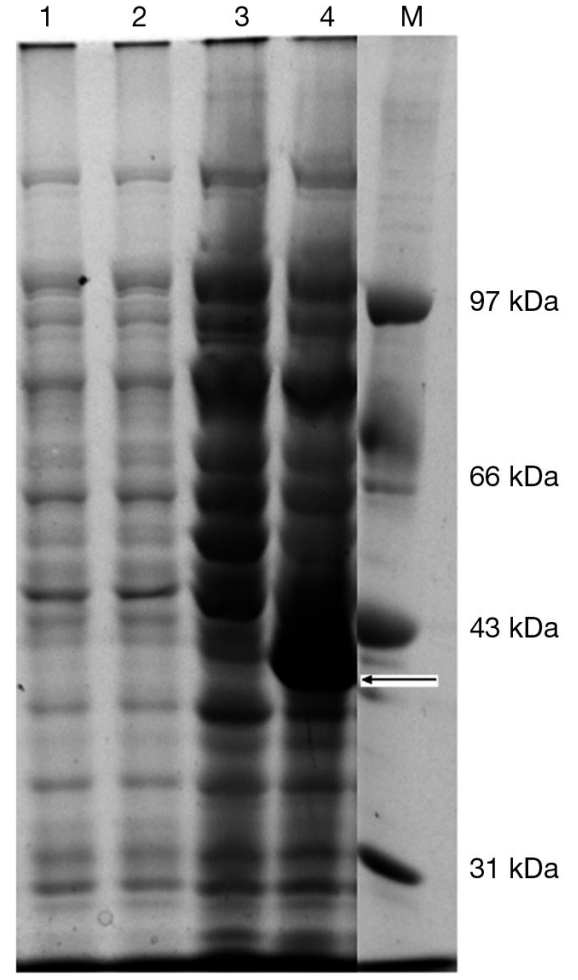

Fig. 1. Sodium dodecyl sulphate polyacrylamide gel electrophoresis (SDS-PAGE) of expressed VP37 in pBAD/gIII A. Lane 1: non-induced $\mathrm{pBAD} / \mathrm{gIII} \mathrm{A}$. Lane 2: non-induced $\mathrm{pBAD} / \mathrm{gIII}$ A-VP37. Lane 3: induced pBAD/gIII A. Lane 4: induced $\mathrm{pBAD} / \mathrm{gIII} \mathrm{A}-\mathrm{VP} 37$. Lane M: protein marker. Arrow indicates target protein

induced pBAD/gIII A-VP37-TOP10 (containing VP37) and induced pBAD/gIII A-TOP10 (containing vector) were analyzed by SDS-PAGE (Fig. 1). Expression protein corresponding to the VP37 envelope protein was observed in the induced pBAD/gIIIA-VP37-TOP10; no protein band was found at the same positions in both the induced and non-induced pBAD/gIII A-TOP10. Western blot analysis showed that anti-His antibody reacted with VP37 protein. This result showed that the VP37 gene was highly expressed in TOP10. Recombinant (His)-tagged VP37 protein was purified using $\mathrm{N}$-affinity chromatograph and the product was called WSSV-VP37. This band reacted with an anti-His antibody (Fig. 2).

\section{Separation of envelope and nucleocapsid proteins}

WSSV virions were incubated with Triton X-100. After extraction, envelopes and nucleocapsids were separated as shown in Fig. 3. This is consistent with previous research (Xie \& Yang 2006). Envelope and nucleocapsid fractions were subjected to SDS-PAGE. 

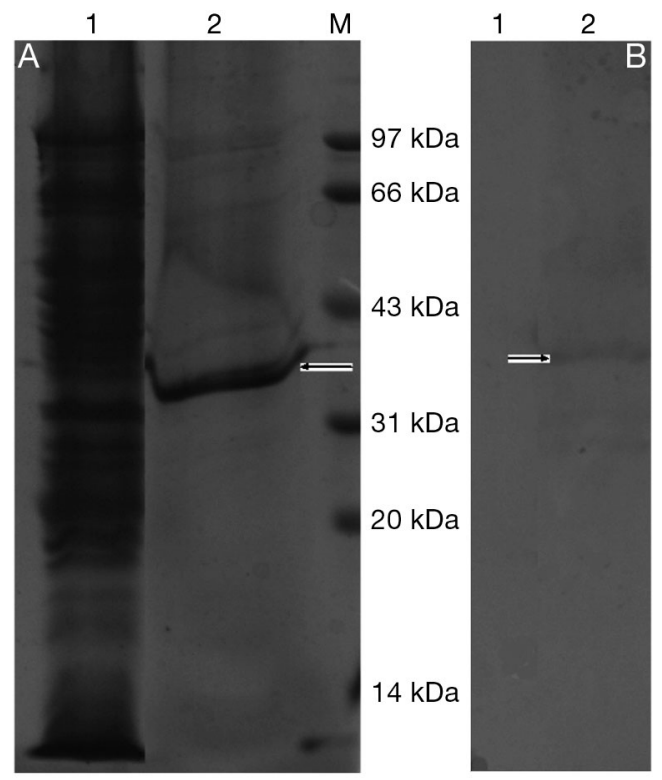

Fig. 2. Western blot analysis of expressed VP37. (A) SDSPAGE of proteins from induced empty vector $\mathrm{pBAD} / \mathrm{gIII}$ A (Lane 1) and purified rVP37 (Lane 2). M: protein marker. (B) Polyvinylidene difluoride (PVDF) membrane blot of (A) treated with anti-His antibody and showing a positive reaction for rVP37. Arrow indicates position of rVP37

Results showed that VP28, VP26, Vp24 and VP19 were the main components of the WSSV envelope, whereas VP15 was contained only in the nucleocapsid (Fig. 4). Interestingly, VP26 was found both in the envelope and nucleocapsid fractions. This suggested that VP26 was not released completely by Triton-X 100 treatment.

\section{VP37 interaction with VP28 and VP26}

For analysis of interaction between VP37 and virions, the viral envelope and nucleocapsid proteins were separated by SDS-PAGE and transferred to PVDF membranes that were then incubated with DIGlabeled VP37 or DIG-labeled BSA. After detection with HRP-conjugated anti-DIG antibody, 2 prominent bands corresponding to VP28 and VP26 were seen in the envelope fractions, and 1 band corresponding to VP26 was seen in the neclocapsid fractions. No band was seen in the BSA control. This result indicated interactions of VP37 with VP28 and VP26 (Fig. 5).

\section{Pull-down analysis}

To test the interaction of VP37 with VP28 or VP26 and to confirm the results of the overlay assay, VP37 and envelope or nucleocapsid proteins were tested by

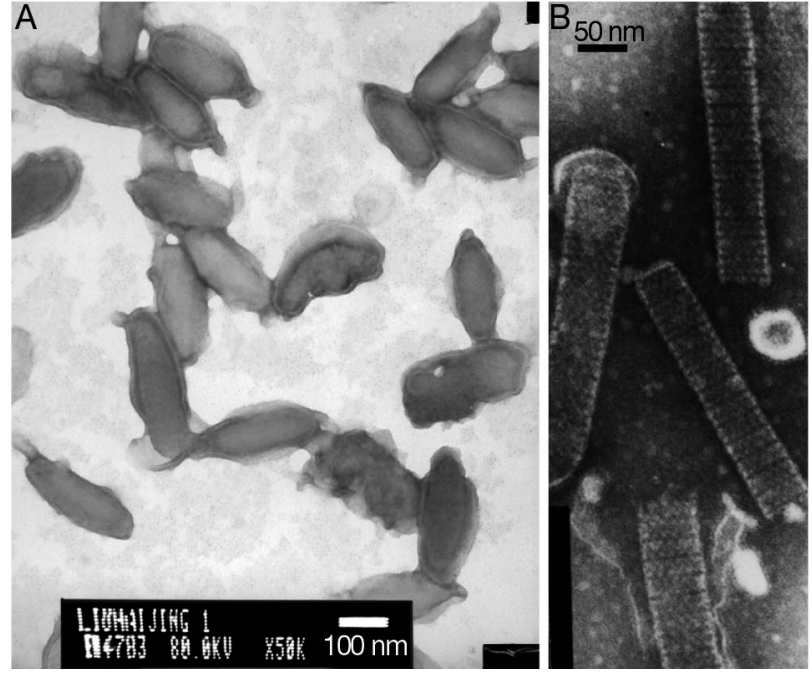

Fig. 3. Electron micrograph of purified (A) white spot syndrome virus (WSSV) envelopes and (B) nucleocapsids

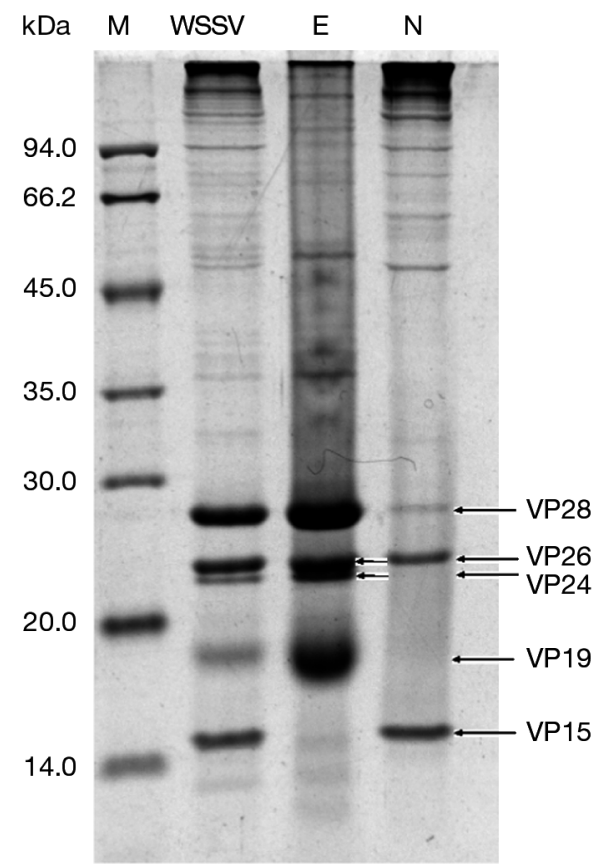

Fig. 4. SDS-PAGE of proteins from purified WSSV and from its Triton-X100-treated envelope (E) and nucleocapsid (N) fractions. M: protein marker. Arrows indicate the major structural proteins VP28, VP26, VP24, VP19, and VP15

an in vitro pull-down assay. His-VP37 was immobilized on Ni-NTA beads and incubated with envelope or nucleocapsid proteins separately. After extensive washing, the elution of His-VP37 contained VP28 in envelope fractions, and VP26 was pulled down both in envelope and nucleocapsid fractions, whereas the control was not (Fig. 6). This supported the contention that VP37 interacted directly with VP28 and VP26. 


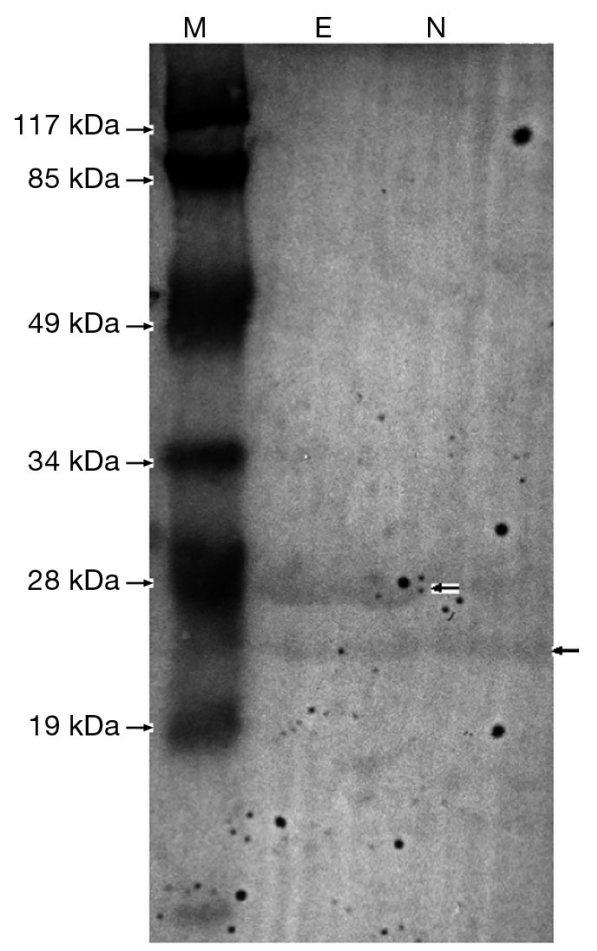

Fig. 5. Western-blot overlay analysis of VP37 interaction with WSSV structural proteins. Membrane of envelope (E) and nucleocapsid (N) proteins overlayed with digoxigenin (DIG)labelled rVP37 and showing positive reactions (arrows) with anti-DIG antibody at 28 and $26 \mathrm{kDa}$. M: protein marker

\section{Mass spectrometry analysis}

To identify the interaction, protein bands were cut out from SDS-PAGE gels and digested by trypsin. Peptide mass fingerprints (PMF) were performed using MALDI-TOF-MS and analyzed by using the MS-FIT system. Band VP28 (Fig.6) from the SDS-PAGE gel showed identical mass spectra: 1367.79, 1415.71, 2203.16, 2219.16, 1542.84, 2711.49, 876.49, 1231.71 Da. All mass spectra were matched with spectra of the VP28 of WSSV in the mass database (Table 1). Band VP26 (Fig.6) from the SDS-PAGE gel showed identical mass spectra: 1313.67, 1543.90, 1935.95, 2776.69 Da. All mass spectra were matched with spectra of the VP26 of WSSV in the mass database (Tables $2 \& 3$ ).

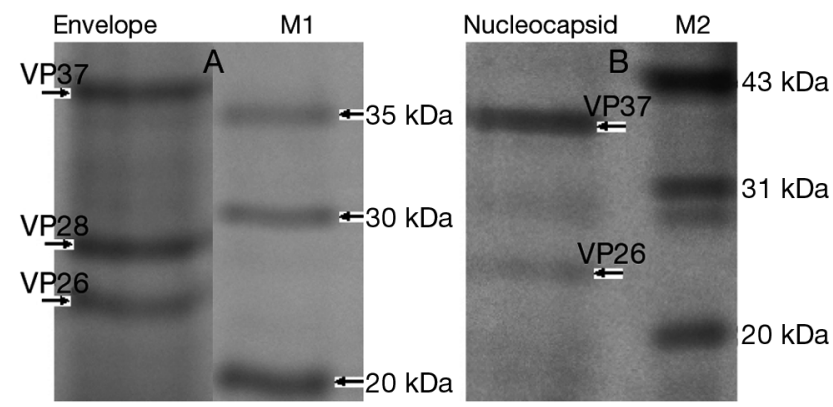

Fig. 6. Results of pull-down assay using His-VP37 coupled to Ni-NTA beads. (A) SDS-PAGE of eluted proteins from the envelope fractions. Envelope proteins were incubated with the beads coupling with VP37; M1: protein marker. (B) SDSPAGE of eluted proteins from the nucleocapsid fractions. Nucleocapsid proteins were incubated with the beads coupling with VP37. M2: protein marker. Arrows indicate VP37, VP28 and VP26

\section{VP28 protein expression and Western blot analysis}

For further analysis of interaction between VP37 and VP28, the VP28 gene was cloned into the pBAD/gIII A vector and expressed in TOP10 cells under induction of $0.2 \%$ L-arabinose. Expressed protein corresponding to the VP28 envelope protein was observed in the induced pBAD/gIIIA-VP28-TOP10. Western blot analysis showed that anti-His antibody reacted with the VP28 protein (Fig. 7). This result showed that the VP28 gene was expressed in TOP10. The recombinant (His)tagged VP28 protein was purified using N-affinity chromatograph and purified VP28 was acquired.

\section{Determination of binding specificity by ELISA}

To determine the specific interaction of VP37 with VP28, ELISA analysis was performed. The results showed that the binding activity of VP37 to VP28 and WSSV was dose dependent (Fig. 8). With the same concentration, VP37 had a higher binding activity with WSSV than VP28. This indicates that VP37 interacted with other WSSV proteins in addition to VP28.

Table 1. Peptide mass fingerprint (PMF) search results of 28 and 26 kDa proteins using Mascot Search with NCBInr databases

\begin{tabular}{|lccccccc|}
\hline Rank & Database & $\begin{array}{c}\text { Accession } \\
\text { name }\end{array}$ & Mass (Da) & $\begin{array}{c}\text { Queries } \\
\text { matched }\end{array}$ & $\begin{array}{c}\text { Protein } \\
\text { description }\end{array}$ & $\begin{array}{c}\text { Score } \\
\text { Sequence } \\
\text { coverage (\%) }\end{array}$ \\
\hline 1 & NCBInr & gil62550917 & 18620 & 13 & WSSV VP28 & 555 & 47 \\
2 & NCBInr & gil62550921 & 23133 & 7 & WSSV VP26 & 237 & 46 \\
\hline
\end{tabular}


Table 2. Matched amino acid sequences of VP28 (GI62550917) by electrospray ionisation-mass spectrometry/mass spectrometry (ESI-MS/MS) analysis. Start-End: position of the sequence; Mr: molecular weight

\begin{tabular}{|lrrrrrl|}
\hline Start-End & \multicolumn{3}{c}{ Mr } & Delta & $\begin{array}{c}\text { Mis- } \\
\text { matches }\end{array}$ & \\
\cline { 2 - 5 } & Observed & Expected & Calc. & & Sequence \\
$22-34$ & 1367.79 & 1366.78 & 1366.71 & 0.07 & 0 & IPVTAEVGSGYFK \\
$35-47$ & 1415.71 & 1414.70 & 1414.63 & 0.07 & 0 & MTDVSFDSDTLGK \\
$55-74$ & 2203.16 & 2202.15 & 2202.05 & 0.10 & 1 & SDAQMKEEDADLVITPVEGR \\
$61-74$ & 1542.84 & 1541.84 & 1541.76 & 0.08 & 0 & EEDADLVITPVEGR \\
$75-91$ & 1854.04 & 1853.03 & 1852.96 & 0.08 & 0 & ALEVTVGQNLTFEGTFK \\
$75-98$ & 2711.49 & 2710.48 & 2710.37 & 0.11 & 1 & ALEVTVGQNLTFEGTFKVWNNTSR \\
$92-98$ & 876.49 & 875.49 & 875.42 & 0.06 & 0 & VWNNTSR \\
$100-110$ & 1231.71 & 1230.70 & 1230.65 & 0.05 & 0 & INITGMQMVPK \\
\hline
\end{tabular}

Table 3. Matched amino acid sequences of VP26 (GI62550927) by electrospray ionisation-mass spectrometry/mass spectrometry (ESI-MS/MS) analysis. Start-End: position of the sequence; Mr: molecular weight

\begin{tabular}{|c|c|c|c|c|c|c|}
\hline \multirow[t]{2}{*}{ Start-End } & 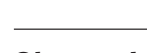 & $-\mathrm{Mr}$ & \multirow[b]{2}{*}{ Calc. } & \multirow[t]{2}{*}{ Delta } & \multirow{2}{*}{$\begin{array}{c}\text { Mis- } \\
\text { matches }\end{array}$} & \multirow[t]{2}{*}{ Sequence } \\
\hline & Observed & Expected & & & & \\
\hline $38-48$ & 1313.67 & 1312.66 & 1312.59 & 0.07 & 0 & SVVANYDQMMR \\
\hline $86-100$ & 1543.90 & 1542.89 & 1542.83 & 0.07 & 0 & DVSADLVISTVTAPR \\
\hline $117-142$ & 2776.69 & 2775.68 & 2775.59 & 0.10 & 0 & ILNNTGVDLLINDITVRPTVIAGNIK \\
\hline $172-189$ & 1935.95 & 1934.94 & 1934.87 & 0.07 & 0 & FEDGAAFEATMNIGFTS \\
\hline
\end{tabular}

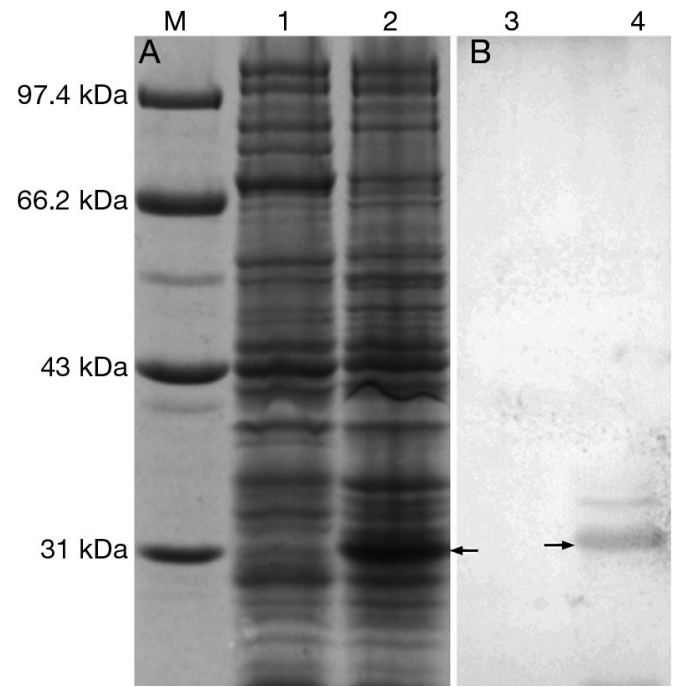

Fig. 7. Western blot analysis of VP28 expressed from vector pBAD/gIII A. (A) SDS-PAGE of expressed proteins from induced bacteria with empty vector (Lane 1) and vector containing VP28 (Lane 2). (B) Western blot of SDS-PAGE from (A) with anti-His antibody. Arrows indicate position of VP28; M: protein marker

\section{DISCUSSION}

In the present study, Triton X-100 was used to extract envelope proteins. VP28, VP19 and VP37 were found exclusively in the envelope fraction, whereas VP15 was found only in the nucleocapsids. Interestingly, VP26 was found both in envelope and nucleocapsid

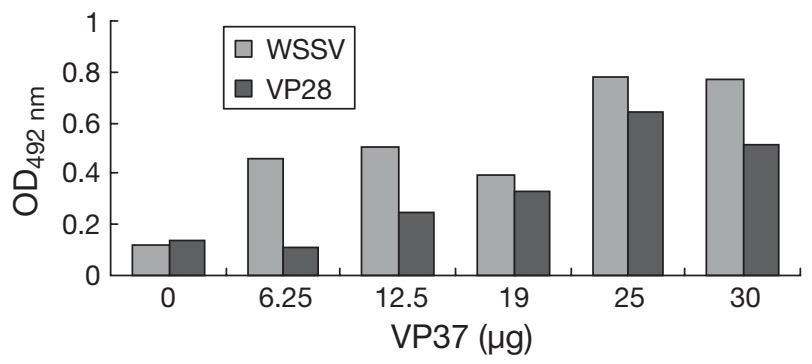

Fig. 8. ELISA analysis of dose-dependent interaction of VP37 (digoxigenin-labeled) with VP28 and WSSV. OD: optical density

fractions. This result agreed with the previous research (Xie \& Yang 2006).

In order to understand the mechanism of WSSV infection and morphogenesis, previous studies focused on the characterization of structural proteins. More than 50 structural proteins of WSSV have been identified (Huang et al. 2002a,b, Xie et al. 2006). VP37 was identified as a WSSV envelope protein using mass spectrometry (Huang et al. 2002). Analysis of its deduced amino acid sequence indicated that VP37 was acidic with an isoelectric point of 4.69 and that it had no significant trans-membrane structure. In addition, a cell attachment sequence Arg-Gly-Asp (RGD motif) was found in VP37. Further research indicated that VP37 could bind to shrimp cells as an attachment protein (Liang et al. 2005, Liu et al. 2006). Neutralization experiments with anti-VP37 antibody revealed that infection by WSSV could be delayed significantly by anti-VP37 
antibody and that VP37 played a role in WSSV infection. Therefore, we were interested in the roles of VP37 in the process of virus assembly. Here we provide evidence that VP37 interacts with VP28 and VP26 directly and that they participate together in viral infection.

We confirmed that VP28 and VP26 are the 2 most abundant structural proteins in the WSSV envelope, accounting for approximately two-thirds of its total protein content (Tang et al. 2007). VP28, VP26, VP24, and VP19 were shown to constitute the major content of the entire envelope (Xie et al. 2006). Both VP28 and VP26 have a predicted trans-membrane region approximately 30 amino acids (aa) in length at the $\mathrm{N}$ terminus. Sequence homology of VP26, and VP28 indicates that these 2 proteins are highly related. The structural similarity of VP26 and VP28 suggests that they may have evolved from a common ancestral gene via duplication. VP26 and VP28 display significant structural homology (Tang et al. 2007). It remains to be determined whether the similar structure of VP26 and VP28 causes the similar interaction with VP37. Previous studies indicated that VP28 could also interact with VP26 and VP24 (Xie et al. 2006). Recent research showed that VP26 of WSSV functions as a linker protein between the envelope and nucleocapsid of virions by binding with VP51 (Wan et al. 2008). And VP51A, a viral envelope protein of WSSV, associated directly with VP26 and indirectly with VP28, with VP26 acting as a linker protein in the formation of a VP51A-VP26-VP28 complex (Chang et al. 2008). More data have accumulated to suggest that VP26 may act as a linker protein to associate these envelope proteins together to form a complex, which may play an important role in viral morphogenesis and viral infection. Since VP37 lacks a trans-membrane domain, we propose that VP37 may anchor to the envelope through interaction with VP26 and VP28 and that they form a complex that participates in viral infection.

It is well known that viral assembly and morphogenesis involve interaction between viral proteins and interaction between the viral and host cell proteins (Garoff et al. 1998, Palucha et al. 2005, Villanueva et al. 2005). Generally, it is a complicated process by which a virus enters the cytoplasm and then initiates replication. There are always many proteins acting as a complex during the entry process. As the Epstein-Barr virus enters B cells, a complex of 3 glycoproteins, $g \mathrm{H}, \mathrm{gL}$, and gp42, are needed for penetration. However, the $\mathrm{gH}$ protein is also an attachment protein that recognizes the cell receptor. At present, it is not clear whether VP37 interaction with VP28 and VP26 is required only for WSSV morphogenesis or whether it is also required for infection. Little is known about the role of the complex in virus binding, entry and assembly. Research on the viral envelope protein interaction may help us to investigate the molecular mechanism of WSSV infection.
Acknowledgements. This study was supported by the National Science Foundation of China (Grant 30871942), the National Basic Research Program (973) of China (Grant 2006CB101801) and the High Technology Development Program of China (863)(Grant 2006AA100312).

\section{LITERATURE CITED}

Chang PS, Chen HC, Wang YC (1998) Detection of white spot syndrome associated baculovirus in experimentally infected wild shrimp, crab and lobsters by in situ hybridization. Aquaculture 164:233-242

Chang YS, Liu WJ, Chou TL, Lee YT and others (2008) Characterization of white spot syndrome virus envelope protein VP51A and its interaction with viral tegument protein VP26. J Virol 82:12555-12564

> Chen LL, Lo CF, Chiu YL, Chang FC, Kou GH (2000) Natural and experimental infection of white spot syndrome virus (WSSV) in benthic larvae of mud crab Scylla serrata. Dis Aquat Org 40:157-161

Chen LL, Wang HC, Huang CJ, Peng SE and others (2002) Transcriptional analysis of the DNA polymerase gene of shrimp white spot syndrome virus. Virology 301:136-147

Chou HY, Huang CY, Wang CH, Chiang HC, Lo CF (1995) Pathogenicity of a baculovirus infection causing white spot syndrome in cultured penaeid shrimp in Taiwan. Dis Aquat Org 23:165-173

> Garoff H, Hewson R, Opstelten DJ (1998) Virus maturation by budding. Microbiol Mol Biol Rev 62:1171-1190

Huang CH, Zhang XB, Lin Q, Xu X, Hew CL (2002a) Characterization of a novel envelope protein (VP281) of shrimp white spot syndrome virus by mass spectrometry. J Gen Virol 83:2385-2392

Huang CH, Zhang XB, Lin Q, Xu X, Hu Z, Hew CL (2002b) Proteomic analysis of shrimp white spot syndrome viral proteins and characterization of a novel envelope protein VP466. Mol Cell Proteomics 1:223-231

Li ZJ, Lin QS, Chen J, Wu JL and others (2007) Shotgun identification of the structural proteome of shrimp white spot syndrome virus and iTRAQ differentiation of envelope and nucleocapsid subproteomes. Mol Cell Proteomics 6: 1609-1620

Liang Y, Huang J, Song XL, Zhang PJ, Xu HS (2005) Four viral proteins of white spot syndrome virus (WSSV) that attach to shrimp cell membranes. Dis Aquat Org 66:81-88

Liu QH, Huang J, Han WJ, Liang Y, Lu C, Wang QY (2006) Expression, purification and characterization of WSSVVP37 in Pichia pastoris. Aquaculture 258:344-349

> Lo CF, Leu JH, Ho Ch and 9 other authors (1996) Detection of baculovirus associated with white spot syndrome (WSBV) in penaeid shrimps using polymerase chain reaction. Dis Aquat Org 25:133-141

> Mayo MA (2002) A summary of taxonomic changes recently approved by ICTV. Arch Virol 147:1655-1656

Palucha A, Loniewska A, Satheshkumar S, BoguszewskaChachulska AM and others (2005) Virus-like particles: models for assembly studies and foreign epitope carriers. Prog Nucleic Acid Res Mol Biol 80:135-168

Szajner P, Jaffe H, Weisberg AS, Moss B (2003) Vaccinia virus G7-L protein interacts with the A30L protein and is required for association of viral membranes with dense viroplasm to form immature virions. J Virol 77: 3418-3429

> Tang XH, Wu JL, Sivaraman J, Hew CL (2007) Crystal structures of major envelope proteins VP26 and VP28 from white spot syndrome virus shed light on their evolutionary relationship. J Virol 81:6709-6717 
Tsai JM, Wang HC, Leu JH, Hsiao HH, Wang AH, Kou GH, Lo CF (2004) Genomic and proteomic analysis of thirty-nine structural proteins of shrimp white spot syndrome virus. J Virol 78:11360-11370

van Hulten MCW, Witteveldt J, Peters S, Kloosterboer N and others (2001a) The white spot syndrome virus DNA genome sequence. Virology 286:7-22

Villanueva RA, Rouillé Y, Dubuisson J (2005) Interactions between virus proteins and host cell membranes during the viral life cycle. Int Rev Cytol 245:171-244

Vlak JM, Bonami JR, Flegel TW, Kou GH and others (2005) Nimaviridae. In: Fauquet CM, Mayo MA, Maniloff J, Desselberger U, Ball LA (eds) Virus taxonomy. Eighth Report of the International Committee on Taxonomy of Viruses. Elsevier, Amsterdam, p 187-192

> Wan Q, Xu LM, Yang F (2008) VP26 of white spot syndrome virus functions as a linker protein between the envelope and nucleocapsid of virions by binding with VP51. J Virol 82:12598-12601

Editorial responsibility: Grant Stentiford, Weymouth, UK
Wang YC, Lo CF, Chang PS, Kou GH (1998) Experimental infection of white spot baculovirus in some cultured and wild decapods in Taiwan. Aquaculture 164: 221-231

Wu W, Wang L, Zhang X (2005) Identification of white spot syndrome virus (WSSV) envelope proteins involved in shrimp infection. Virology 332:578-583

Xie X, Yang F (2006) White spot syndrome virus VP24 interacts with VP28 and is involved in virus infection. J Gen Virol 87:1903-1908

> Xie X, Li HY, Xu LM, Yang F (2005) A simple and efficient method for purification of intact white spot syndrome virus (WSSV) viral particles. Virus Res 108:63-67

> Xie X, Xu LM, Yang F (2006) Proteomic analysis of the major envelope and nucleocapsid proteins of white spot syndrome virus. J Virol 80:10615-10623

Yang F, He J, Lin X, Li Q, Pan D, Zhang XB, Xu X (2001) Complete genome sequence of the shrimp white spot bacilliform virus. J Virol 75:11811-11820

Submitted: October 27, 2008; Accepted: February 23, 2009 Proofs received from author(s): April 20, 2009 